PALABRAS CLAVE

Crisis económica

Crisis financiera

Política económica

Modelos de desarrollo

CEPAL

Desarrollo económico

América Latina

Gert Rosenthal

Secretario Ejecutivo de la CEPAL, 1988-1997

Actual Representante Permanente de

Guatemala ante las Naciones Unidas

grosenthal61@hotmail.com
REVISTA CEPAL 100 ABRIL 2010

\section{La crisis financiera y económica de 2008 y su repercusión en el pensamiento económico}

\author{
Gert Rosenthal
}

L.

crisis financiera y económica de 2008 tuvo múltiples consecuencias en los países de América Latina y el Caribe. Trastocó el desempeño de las economías y puso en duda paradigmas que habían orientado la política económica en la mayoría de los países. Asimismo, exacerbó crecientes divergencias entre puntos de vista surgidos incluso antes de la crisis. Algunas de esas divergencias son de carácter ideológico, pero otras obedecen a enfoques antagónicos sobre estrategias económicas. Entre los factores de diferenciación se encuentran, primero, el papel del Estado y su relación con el mercado, y segundo, la naturaleza y alcance de la inserción en la economía global. Aquí se abordan algunos de los rasgos de diferenciación, las tensiones que generan y el futuro que deparan para la cooperación dentro de América Latina. También se señala que en este nuevo escenario, marcado por cierta perplejidad, se abren espacios inherentes al trabajo de la CEPAL. 


\section{I}

\section{Introducción}

Sin lugar a dudas, la crisis financiera y económica de 2008 , precedida por la doble crisis que afectó a los mercados energéticos y alimenticios, será recordada como un evento divisor, pues puso de manifiesto las vulnerabilidades de la globalización, empujó la economía global al borde del abismo, causó grandes penurias a decenas de millones de seres humanos y, de paso, exacerbó viejas disputas y tensiones acerca de cómo abordar el desarrollo. El tema de la crisis ha sido objeto de una abundante literatura en círculos académicos, en organismos internacionales e incluso en los medios de comunicación social; en la propia CEPAL se ha hecho una labor meritoria al analizar el origen de la crisis, su propagación, su impacto y sus posibles consecuencias a futuro (CEPAL, 2009a, 2009b, 2009c y 2009d). Acaso menos estudiadas han sido las disputas y tensiones que esa crisis intensificó en el dominio económico, y ese será precisamente el foco central de este trabajo desde la óptica latinoamericana. En términos generales, el debate gira en torno del rol del Estado en el marco de los distintos paradigmas de desarrollo; en términos más puntuales, se destacarán dos ámbitos: la discusión sobre cómo abordar la equidad social y la creciente polarización en el interior de los foros multilaterales.

\section{II}

\section{El trasfondo inmediato}

La irrupción de la crisis financiera de 2008 no solo alteró el desempeño de las economías de la región, sino que puso a prueba paradigmas de política económica que se venían aplicando desde hace algún tiempo, con diferencias de contenido e intensidad de un país a otro. Asimismo, al repercutir de manera diferenciada en distintos grupos en el interior de cada país, y también entre países, los efectos de la crisis generaron o aumentaron tensiones preexistentes, influyendo - entre otros aspectos- en el contenido, alcance y tono de las relaciones internacionales. Ante todo, las respuestas diferenciadas agudizaron el debate sobre cómo organizarse para salir del atolladero actual y estar en condiciones de cumplir con las aspiraciones universales tan elocuentemente recogidas en los objetivos de desarrollo del Milenio.

Desde esa óptica, muchos observadores han señalado, no sin cierta satisfacción perversa, que después de décadas de escuchar "lecciones" de los principales centros económicos del mundo, incluidas las instituciones financieras multilaterales, sobre cómo conducir de manera responsable y coherente la gestión macroeconómica para evitar las crisis periódicas que caracterizaban a la región, en esta ocasión se invirtió el escenario y los predicadores de antaño resultaron ser los irresponsables. En tanto que sus ex pupilos latinoamericanos, que en general sí actuaron con profesionalismo, fueron los que tuvieron que pagar los "platos rotos" de la crisis gestada en el mero centro del capitalismo, sin haber tenido la más mínima responsabilidad en su génesis. Para una región que muchas veces encubría sus insuficiencias en materia de gestión económica achacando la responsabilidad de su desempeño insatisfactorio a fenómenos de origen internacional, la "culpa" en esta ocasión sí provenía innegablemente del sector externo.

A su vez, a la luz de la crisis, muchos analistas, individuales e institucionales, incluida de manera destacada la propia Comisión Económica para América Latina y el Caribe (CEPAL), se han sentido reivindicados en su análisis de los últimos años. Por una parte, ellos han advertido persistentemente la insostenibilidad de los desequilibrios financieros que se estaban gestando en la economía mundial, sobre todo entre los Estados Unidos y algunos de sus socios comerciales superavitarios. ${ }^{1}$ Por otra, han formulado cuestionamientos al paradigma económico en boga desde los años ochenta, justamente por su sobrevaloración del papel del mercado y su subvaloración del papel del Estado en el desempeño económico y social.

\footnotetext{
${ }^{1}$ Véanse, entre otros, CEPAL (2006a, p. 31; 2007a, pp. 35 y 36; y 2007b, p. 24).
} 
En ese sentido, durante los últimos 20 años la CEPAL ha contribuido al debate sobre paradigmas del desarrollo, profundizando su vocación como ente generador de posiciones heterodoxas, cuestionando o avalando los postulados de las ortodoxias de distinto signo, y atendiendo a las especificidades y rasgos característicos de los patrones de desarrollo de la región y sus diferentes tipos de economías. ${ }^{2}$ Esta vocación ha sido particularmente relevante a partir de 1990 en el debate económico referido a los modelos vigentes, y a la crítica que efectuaban diversos sectores sobre la forma mecánica con que se aplicaban sus preceptos. ${ }^{3}$ En sus términos más sencillos, un eje central del análisis giraba en torno de la idea de que las señales del mercado por sí solas no resolverían todo; se abogaba, más bien, por una combinación juiciosa entre mercado y Estado para lograr los múltiples objetivos del desarrollo, incluidos el crecimiento económico, una mayor equidad, la estabilidad financiera y la sostenibilidad ambiental.

El detonador de la gran crisis financiera de 2008, que se puede atribuir, en gran parte, al deficiente funcionamiento del mercado (para decir lo menos) y a la virtual ausencia del Estado en cuanto al cumplimiento de su papel regulador, sin duda alentará a los agnósticos de la ortodoxia pura a persistir en la búsqueda de acomodos que les permitan acceder al desarrollo en un contexto internacional cada vez más complejo y alborotado.

\section{III}

\section{Tensiones y polarización de posiciones}

Pero el panorama se complica aún más si se toma en cuenta la creciente heterogeneidad de enfoques que se está generando en América Latina, no solo acerca de cómo abordar las estrategias y políticas económicas, sino de cómo visualizar el papel de la región en el contexto internacional, a lo que deben sumarse las diferencias de agenda política en situaciones tan diversas como las que se presentan entre los distintos países. La principal línea divisoria del debate en materia económica antecede a la crisis de 2008, y se construye alrededor de la manera en que los distintos países procuran insertarse en la economía internacional. En términos esquemáticos (la realidad siempre es más compleja y matizada), los dos "polos" extremos en una amplia gama de posiciones serían los siguientes: por una parte, se encuentran aquellos países intensamente comprometidos con la apertura y la liberalización comercial (pero no todos ellos se entregaron a la liberalización financiera simultánea, como lo postulaba el paradigma entonces en boga). Son estos países los que procuraban aproximarse a los principales mercados desarrollados, y particularmente al de los Estados Unidos, por medio de acuerdos de libre comercio. Por definición,

\footnotetext{
2 Véanse CEPAL (1990, 1994a, 1996 y 1998) y Torres (2006).

${ }^{3}$ Para un penetrante análisis sobre la diferenciación entre el paradigma vigente en los años noventa y la propuesta cepalina, véase la entrevista de Fernando Fernández a Fernando Fajnzylber (Fernández, 1994, pp. 207-209).
}

son países dispuestos a someterse en gran medida a los dictados de la economía de mercado.

Por otra parte, están aquellos países que buscan una mayor autonomía - de la economía internacional y de la estadounidense en particular- y menor dependencia de las señales del mercado. En efecto, la entonces llamada "Alternativa Bolivariana para las Américas (ALBA)", suscrita entre Cuba y la República Bolivariana de Venezuela en diciembre de 2004, se ofreció en un principio como una alternativa al Acuerdo de Libre Comercio de las Américas (ALCA), que a partir de la primera Cumbre de las Américas, celebrada en la ciudad de Miami en diciembre de 1994, pretendía erigir una zona de libre comercio de alcance hemisférico (pero excluyendo precisamente a Cuba, por razones conocidas).

Como se sabe, esta última iniciativa nunca se concretó ante la resistencia de algunos países de la región, cada uno movido por razones e intereses distintos. Pero el fracaso de la iniciativa original dio origen a un conjunto de acuerdos de libre comercio de alcance geográfico acotado, que se sumaron al Tratado de Libre Comercio de América del Norte suscrito previamente entre México, Canadá y los Estados Unidos. Esos acuerdos han sido puestos en vigor en Chile, los países centroamericanos, la República Dominicana y el Perú, mientras que Colombia y Panamá aún esperan sumarse a aquellos. La línea divisoria entre los países que mantienen acuerdos de libre comercio (TLC) con los Estados Unidos y los que proponen una "alternativa" cobró un relieve ideológico y político adicional en cuanto al modo en que los 
distintos países interactuaban con los Estados Unidos, que el propio portal de la red del ALBA plantea - no sin un sesgo ofensivo - como "una propuesta imperialista de dominación enfrentada a una propuesta patriótica de liberación" (Rossi, 2009).

Algunos analistas también han agregado una dimensión geográfica a esta nítida división en materia económica, política e ideológica. Por una parte, señalan a los países latinoamericanos ubicados en el "arco del Pacífico", muy proclives a la apertura y cada vez más insertos en la economía global. Por otra, a aquellos ubicados en el Atlántico -incluidos los miembros originales del Mercado Común del Sur (Mercosur), en una situación intermedia entre los países del ALBA y los países que mantienen TLC con los Estados Unidos- un tanto menos proclives a la apertura, aunque cada uno por razones distintas. Y un caso singular sería el de Brasil, dados su creciente protagonismo y participación en la economía global, además de la dimensión de su mercado doméstico (CEPAL, 2006b, p. 86).

Antes de proseguir, cabe señalar que las divisiones descritas de ninguna manera son rígidas, ya que persiste una vasta urdimbre de vasos comunicantes entre países que trascienden aquellas divisiones. Esos vasos comunicantes surgen de relaciones comerciales y financieras, intereses comunes, pertenencia a distintas agrupaciones formales tales como la Unión de Naciones Suramericanas (UNASUR), el Grupo de Río, el Sistema Económico Latinoamericano (SELA), la Corporación Andina de Fomento (CAF) y el Mercosur más sus miembros asociados. Incluso hay un país - Nicaragua - que, en un acto insigne de malabarismo, mantiene un TLC con los Estados Unidos y a la vez es miembro del ALBA. Asimismo, todos los países de la región cultivan relaciones bilaterales con Cuba, el gran ausente (hasta ahora) de los foros interamericanos, pero que continúa siendo fuente de inspiración para numerosos latinoamericanos, que, entre otros aspectos, perciben la resistencia de ese país ante "el Imperio" como un símbolo de gran dignidad.

Sea como fuere, esta creciente división en el interior de América Latina y el Caribe que, como se dijo, precedía a la crisis de 2008, fue notoriamente agudizada por aquella crisis. Así, el fuerte tono de denuncia contra el "modelo neoliberal" que acompañaba al discurso del ALBA (hoy denominada "Alianza Bolivariana para los Pueblos de Nuestra América") encontró en la crisis la confirmación de sus frecuentes vaticinios, anunciando de este modo poco menos que la defunción del capitalismo. ${ }^{4}$ Ciertamente,

${ }^{4}$ En la Declaración Final que emanó de la Cumbre Extraordinaria del ALBA, celebrada en Cumaná, Venezuela, el 17 de abril de 2009, los ese discurso tenía algún fundamento objetivo. La crisis sirvió para desmitificar las exageradas expectativas de que el mercado contenía mecanismos propios de autocorrección contra la especulación, y a la postre puso al descubierto las graves falencias de los mecanismos de regulación y supervisión de las principales economías industrializadas, para no mencionar las casi inexistentes entidades reguladoras a nivel internacional. También se constató el inmenso riesgo que plantea la exagerada participación de los capitales golondrina en los flujos financieros internacionales.

Por añadidura, el hecho de que la crisis naciera en el "Imperio" subrayaba una vez más, en la óptica de los interlocutores del ALBA, que de allí fluyen muchos de los males que aquejan a la región. En consecuencia, no es de extrañar que los países que ya abrigaban serias dudas sobre el ordenamiento de la economía internacional previo a la crisis -incluida de manera explícita su inconformidad con el papel de las instituciones de Bretton Woods - llegaran ahora a la conclusión de que todas las falencias advertidas en el funcionamiento del mercado precisaban nada menos que un nuevo modelo. Esta posición contrastaba con la de aquellos países que se conformaban simplemente con acomodos, aunque fuesen acomodos importantes.

Es más, aquellos países detractores creen encontrar en la crisis una reivindicación adicional, al constatar que las economías latinoamericanas, cuyo sector exportador es más dependiente del mercado estadounidense, son las que fueron más duramente golpeadas al verse arrastradas por los efectos recesivos de aquella economía. Si bien resulta difícil establecer relaciones de causalidad entre la evolución de la economía estadounidense y la de distintos países de la región, es innegable que el alto grado de interdependencia económica entre los Estados Unidos y México es uno de los factores que explica la dramática caída en el nivel de actividad económica en este último país en 2009, aunque con signos de recuperación en el último trimestre (CEPAL, 2009e).

Así las cosas, en el mundo de las ideas la crisis se presenta como el detonador de un renovado debate en la región sobre cómo abordar su desarrollo. Ese debate incluso tiene rasgos de polarización que hacen recordar, guardando las distancias en el tiempo y considerando el enorme cambio de contexto, la discusión de los años sesenta y setenta del siglo anterior sobre las virtudes e

Presidentes afirmaron: "El capitalismo está acabando con la humanidad y el planeta. Lo que estamos viviendo es una crisis económica global de carácter sistémico y estructural, y no una crisis cíclica más”. Más adelante en el texto se habla de la "decadencia del capitalismo". 
inconvenientes de las economías centralmente dirigidas versus las economías de mercado, con las "economías mixtas" ocupando el espacio intermedio, cada una con sus matices peculiares. En el contexto de la globalización, las antípodas se encuentran —de nuevo, en términos esquemáticos-, por una parte, en la agenda del ALBA y, por otra, en aquellos países que se empecinan en continuar con la estrategia vigente en los últimos tiempos, sin mayores acomodos. El resto de los países - por ahora la mayoría, al no haber abrazado nunca la ortodoxia "pura" - ocupan espacios intermedios en que postulan redefinir la frontera entre mercado y Estado, también con variantes singulares de un país a otro. Ellos continúan construyendo sobre los considerables logros registrados en los últimos años mediante su inserción en la economía global, soslayando plantearse golpes de timón sustanciales en sus estrategias de desarrollo. Dicho de otra manera, el panorama actual hace recordar una época que parecía superada, en que se enfrentaban las estrategias "aperturistas" con el "desarrollo hacia adentro"; o el socialismo contra el capitalismo, con los reformistas ocupando el espacio intermedio e intentando aprovechar las virtudes de ambos planteamientos y eliminando sus supuestos inconvenientes.

\section{IV}

\section{Parámetros del debate}

Sin embargo, lo que todavía no queda muy claro es el contenido y alcance de las estrategias que se enfrentan. Por una parte, el modelo de lo que el Presidente Hugo Chávez llama el "socialismo del siglo XXI" se define mejor por lo que no es que por sus características de carácter propositivo. En ese sentido, sí queda claro el rechazo categórico del modelo al que se proclama difunto (el "neoliberal"). En cuanto al grupo de países dispuestos a continuar el rumbo general de las políticas de los últimos tiempos, si bien existe mayor claridad sobre las modalidades precisas del modelo aperturista, no se perfilan con nitidez los rasgos de las mutaciones que a futuro se incorporarán al modelo para adaptarlo a las nuevas circunstancias internas e internacionales que surgirán a consecuencia de la crisis.

En relación con el carácter propositivo, la llamada "Alternativa Bolivariana" se presenta con un mayor contenido doctrinario que el relativo pragmatismo que caracteriza al modelo aperturista. En lo que atañe al ámbito económico, en ella se valora la solidaridad más que el egoísmo o el afán de lucro; se otorga prelación al papel del Estado por sobre el de la actividad privada, y se postula la inclusión, la participación, el igualitarismo y el combate a la pobreza como valores irrenunciables. Asimismo, en dicha alternativa se observa con algún recelo la apertura comercial guiada por las señales del mercado, y se pretende mitigar sus efectos por medio de un intercambio comercial equilibrado - a veces apoyado en un modelo de comercio administrado que recuerda los viejos tiempos del Consejo de Ayuda Mutua Económica (CAME) - entre los países miembros del ALBA y entre estos y otros países no pertenecientes a la Alianza. También se valora la cooperación Sur-Sur, una de cuyas expresiones concretas más elocuentes se encuentra en el Acuerdo de Cooperación Energética PETROCARIBE impulsado por el Gobierno de la República Bolivariana de Venezuela, así como en programas de cooperación bilateral que tanto este país como Cuba proveen a muchos países, sobre todo en el área de salud. ${ }^{5}$

Estos enunciados generales de cambiar tanto el paradigma de desarrollo como el orden económico internacional todavía no se articulan en una propuesta programática integral y con coherencia interna. Es decir, los enunciados retóricos aún no se traducen en planteamientos susceptibles de ser instrumentados, como se colige de la siguiente frase que nuevamente pone el énfasis en describir lo que no es: "es necesario desarrollar un modelo alternativo al sistema capitalista. Un sistema de solidaridad y complementariedad y no de competencia; un sistema de armonía con nuestra madre tierra y no de saqueo de los recursos naturales; un sistema de diversidad cultural y no de aplastamiento de culturas e imposición de valores culturales y estilos de vida ajenos a las realidades de nuestros países; un sistema de paz basado en la justicia social y no en políticas y guerras imperialistas". ${ }^{6}$ Desde luego, el llamado a la transformación profunda implícito en las frases anteriores, que encierra objetivos sin duda loables, también tiene un importante trasfondo político e ideológico, además de

\footnotetext{
5 Ya son 18 los países beneficiarios del Acuerdo PETROCARIBE, un esquema novedoso de cooperación.

${ }^{6}$ Extraído de la Declaración Final de la Cumbre Extraordinaria del ALBA, celebrada en Cumaná, Venezuela, el 17 de abril, 2009.
} 
inspirarse en una veta nacionalista y reivindicativa de la unidad latinoamericana.

Al mismo tiempo, muchos de esos enunciados, comprendidos aquellos relacionados con la inclusión, la participación y el combate a la desigualdad absoluta y relativa, son comunes con las estrategias de desarrollo de los países que apuestan a mejorar su inserción en la economía internacional, por lo que el principal elemento de diferenciación entre los enfoques antagónicos en materia de política económica tiene que ver con el secular debate sobre el rol del Estado y su relación con el mercado. A ello se yuxtaponen desde luego diferencias ideológicas o doctrinarias más pronunciadas.

En síntesis, la región se enfrenta a dos enfoques bastante antagónicos sobre cómo abordar su desarrollo futuro, con una amplia gama de enfoques intermedios. En un extremo se postula una especie de "borrón y cuenta nueva" cuyos contornos precisos son difíciles de discernir; en el otro, la aceptación de que las estrategias hasta ahora aplicadas para insertarse en la economía internacional apuntan en la dirección correcta, aunque precisan de acomodos constantes, sobre todo a raíz de las crisis múltiples de 2008. Al tratar de caracterizar los enfoques antagónicos se entra a terrenos bastante resbaladizos, no solo por las razones expuestas en el acápite anterior, sino porque cada uno de los países de la región incorpora ciertas peculiaridades a su gestión macroeconómica y a sus políticas sociales, acordes con la realidad y las circunstancias que imperan, así como con el sesgo ideológico de la administración de turno.

En todo caso, lo que sí queda claro es que la crisis de 2008 marca el final de un período en que la gran mayoría de los países de la región se sumaron a una corriente principal en materia de estrategias y políticas económicas, con distintas variantes de un país a otro. Algunos tildan esas estrategias y políticas económicas como "neoliberales", otros como el Consenso de Washington, e incluso otros como la respuesta nacional a los desafíos de la globalización. Si bien con bastantes matices, en líneas gruesas la política económica en la gran mayoría de los países apuntaba más o menos en la misma dirección. Por cierto, lo mismo se podría decir de las décadas de 1950 y 1960, cuando el paradigma cepalino era el que constituía el mainstream y fue cuestionado por la ortodoxia, que empezó a imponerse en los años setenta contribuyendo a una dispersión de enfoques similar — guardando las distancias— al fenómeno que se vive en la actualidad y que probablemente se acentuará en el futuro inmediato (Fishlow, 1985).

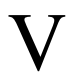

\section{Las propuestas antagónicas ante la inequidad}

Una de las críticas más persuasivas al llamado "modelo neoliberal" ha sido respecto de su carácter concentrador y excluyente. La tesis ortodoxa según la cual el crecimiento económico, combinado con la "magia del mercado", derramaría sus beneficios hacia abajo por efecto de filtración (trickle-down) en favor de todos los estratos de ingresos, ha sido desacreditada desde hace mucho tiempo. Por eso, la CEPAL viene insistiendo a lo largo de décadas sobre la importancia de suplementar las señales del mercado con políticas específicas para que el crecimiento sea más equitativo. ${ }^{7}$ Los rezagos sociales y la inequidad en América Latina también constituyen los fundamentos más ampliamente postulados por aquellos que invocan el "socialismo del siglo XXI" para atender a los estratos de menores ingresos, invocando los éxitos que ofrece Cuba a través de sus innegables logros en esta materia durante varias décadas (CEPAL, 2000).

\footnotetext{
${ }^{7}$ Véase, por ejemplo, CEPAL (1994b).
}

No sorprende que el combate a la desigualdad convoque tanta atención. Como se sabe, existe un inmenso caudal de literatura sobre la pobreza absoluta y relativa en la región, las estrategias para abordarlas, y acerca de cómo conciliar los objetivos de crecimiento con aquellos de la equidad. La atención prioritaria de este propósito no reconoce signo ideológico. Incluso han surgido propuestas para potenciar ("empoderar") a los pobres cuyo origen intelectual se puede encontrar en conceptos abrazados por los grupos relativamente más conservadores en el espectro ideológico latinoamericano. Esos conceptos incluyen la confianza en el funcionamiento del mercado, el rol fundamental del estado de derecho y un ambiente amigable al desenvolvimiento de la pequeña empresa. ${ }^{8}$

\footnotetext{
${ }^{8}$ Véase, por ejemplo, Comisión para el Empoderamiento Jurídico de los Pobres (2008). La Comisión fue copresidida por Madeleine Albright y Hernando de Soto.
} 
También es verdad que América Latina y el Caribe es, en promedio, la región que revela mayor desigualdad entre todas las regiones en desarrollo (Banco Mundial, 2005, pp. 4-8 y 66; Lustig, 2009, p. 1). Es cierto, asimismo, que si bien hasta los años noventa el crecimiento económico solía facilitar la reducción de la incidencia de la pobreza (es decir, de la pobreza absoluta), en la mayoría de los casos la distribución del ingreso (la pobreza relativa) solía estancarse o incluso empeorar (CEPAL, 1997; La Fuente y Sáinz, 2001, pp. 161-170). Pero es precisamente en este ámbito donde se han producido algunos cambios en los últimos tiempos, que, cuando menos, llaman poderosamente a la reflexión.

Así, resulta relevante reconocer los significativos avances registrados en muchos países de la región que mostraron cierto pragmatismo al combinar elementos del paradigma en uso, sobre todo en materia de gestión macroeconómica y de fortalecimiento del estado de derecho, con políticas novedosas para enfrentar los rezagos sociales que constituyen el principal "talón de Aquiles” del desempeño económico de la región. Esta combinación juiciosa de mercado con Estado empezaba a rendir logros nada despreciables en la región, sobre todo si se contrasta la situación de algunos países en, digamos, el año 2008 con la situación de esos mismos países 10 años atrás. Incluso se podría sostener que algunas naciones soportaron los efectos devastadores de la crisis financiera y económica con mejor capacidad de resistencia y con más fuerza de lo que se preveía hace tan solo unos meses, al menos a juzgar por el desempeño previsto para 2010 (CEPAL, 2009e).

Pero lo que resulta aun más pertinente para los efectos de este trabajo, es que se registraron avances significativos en el abordaje de los rezagos sociales. Así, la incidencia de la pobreza en la región en su conjunto bajó de alrededor del $44 \%$ al $33 \%$ en una década —entre finales de los años noventa y 2008-, mientras que la incidencia de la pobreza extrema descendió del $19 \%$ al 13\% (CEPAL, 2009f, pp. 3-12). Igual o acaso más significativo es que por primera vez se reportan mejoras generalizadas en la distribución del ingreso, atribuibles en parte al efecto compensador de la política pública en la tendencia concentradora del crecimiento registrado en períodos pretéritos. ${ }^{9}$ Según un reciente informe de la CEPAL, de un universo de 18 países que disponen de datos, 15 reportaron una mejora en la distribución del ingreso (CEPAL, 2009f, pp. 12-17).

Según ese mismo informe, los avances consignados se deben, entre otros aspectos, a los siguientes factores: primero, la expansión económica combinada con crecientes niveles de generación de empleo; segundo, una gradual pero significativa mejora en la capacidad financiera de los Estados, lo que permitió, entre otros avances, un fuerte aumento - cuantitativo y también cualitativo- en el gasto social; tercero, la aplicación de políticas distributivas bastante creativas, como por ejemplo, los programas de transferencias monetarias y las transferencias condicionadas (Madariaga, 2009); y, cuarto, los efectos favorables (y previsibles) de la transición demográfica presente en la mayoría de los países de la región, con decrecientes índices de dependencia por trabajador ocupado (CEPAL, 2009f). También se sumaron a estos factores los efectos acumulativos del aumento en el gasto social, y en especial en educación, ya que la brecha salarial - la distancia que separa a los estratos mejor remunerados de los peor remunerados-al parecer está disminuyendo en muchos países como reflejo de aquel fenómeno (López Calva y Lustig, 2009).

En resumen, las estrategias de desarrollo asumidas por aquellos países de la región que optaron por el modelo "aperturista", combinando juiciosamente la intervención pública con las fuerzas del mercado, al parecer han producido resultados iguales o aun más satisfactorios en el combate a la pobreza y el mejoramiento de la distribución del ingreso que los registrados en los países que vienen criticando aquella estrategia por su carácter notoriamente concentrador (Lustig y McLeod, 2009). Al mismo tiempo, es importante reconocer que los impresionantes avances registrados en algunos países no son comunes a todas las economías de la región, ni que la capacidad de resistencia a los efectos de la crisis fue generalizada.

\footnotetext{
${ }^{9}$ Véase, por ejemplo, Soares y otros (2009, pp. 207-224).
} 


\section{VI}

\section{Las propuestas antagónicas ante el ordenamiento internacional}

La otra materia en que se evidencia una polarización de posiciones en el interior de la región se refiere a la actitud de los distintos gobiernos ante el ordenamiento institucional de la economía internacional. Si bien los países que optaron por el modelo de apertura han expresado serias reservas sobre los sistemas de gobernabilidad de las instancias existentes, con su actitud suelen postular la corrección de esas falencias mediante reformas de las instituciones. ${ }^{10}$ En cambio, otros países de la región, liderados por los miembros del ALBA, plantean reformas mucho más radicales e incluso la sustitución de aquellas instituciones por algo distinto, que suele caracterizarse como más transparente y más democrático. ${ }^{11}$

La línea divisoria no es nítida: todos los países de la región denuncian el ordenamiento institucional existente, e incluso todos asignan cuotas de responsabilidad a las instituciones financieras existentes, y muy particularmente al Fondo Monetario Internacional. Asimismo, todos advierten grandes lagunas en ese ordenamiento internacional, que depende en alto grado de una sola moneda de reserva (el dólar) y que carece de muchos mecanismos de coordinación. ${ }^{12}$ Pero la diferenciación también tiene rasgos claros. En un extremo se encuentran los países que virtualmente culpan a esas instituciones de "imponer" el modelo que condujo a la ruina, y desean suprimirlas, asignando sus funciones a otras instancias más democráticas y universales, como las Naciones Unidas. En el otro, se hallan los países que han expresado diferentes categorías de cuestionamientos a las prácticas de trabajo de esas instituciones y sobre todo a su sistema de gobernabilidad, pero no al extremo de plantear su

\footnotetext{
${ }^{10}$ Basta acudir al portal en la red del Grupo Intergubernamental de los 24 (ttp://www.g24.org/) y revisar algunos de los documentos que allí aparecen para confirmar la anterior aseveración.

11 "Se requiere establecer un nuevo orden económico internacional, basado en la solidaridad, la justicia, la equidad y el desarrollo sostenible. La arquitectura financiera internacional debe ser refundada. A las Naciones Unidas, y en particular a esta Asamblea General, corresponde un papel central en este esfuerzo". Discurso del Ministro de Relaciones Exteriores de Cuba, Bruno Rodríguez Parrilla, en el debate general del $64^{\circ}$ período de sesiones de la Asamblea General, 28 de septiembre, 2009 (http://www.un.org/ga/64/generaldebate/CU.shtml).

12 Un excelente ensayo que cubre esta temática fue elaborado por José Antonio Ocampo bajo el título "Rethinking Global Economic and Social Governance (Ocampo, 2009).
}

supresión. Más bien, esos países se limitan a postular cambios, incluso cambios importantes, en el sistema de gobernabilidad y en las prácticas normativas de aquellas instituciones, considerando a veces la creación de nuevas instancias internacionales. Así, por ejemplo, una idea que está recibiendo creciente atención es la de crear una instancia internacional que actúe como una especie de Consejo Económico rector de todos los organismos multilaterales en el ámbito económico y financiero. ${ }^{13}$

Como un tema paralelo, un grupo de países critica severamente el surgimiento del Grupo de los Veinte (G-20) como la extensión del sistema de dominación y exclusión presente en el ordenamiento financiero internacional. Otros países de la región aceptan este foro informal -algunos con resignación- como un avance, al incorporar en su seno a economías emergentes de creciente protagonismo, $\mathrm{y}$ al haber actuado con agilidad en promover una respuesta concertada, coordinada y oportuna a la crisis. ${ }^{14}$ Es más, algunos ven en este incipiente foro el embrión de una eventual instancia como el Consejo Económico descrito en el párrafo anterior. De nuevo, la manera en que los países de América Latina y el Caribe se ubican ante esta dimensión internacional de la crisis tiende a posiciones altamente divergentes.

Todas estas divergencias se hicieron patentes durante la concepción, preparación y celebración de la llamada Conferencia de las Naciones Unidas sobre la crisis financiera y económica mundial y sus efectos sobre el desarrollo. La mera decisión de celebrar este evento nació bajo la sombra de una fuerte controversia entre aquellos países que deseaban rescatar para las Naciones Unidas el papel rector del ordenamiento financiero y económico internacional, y aquellos que insistían en que ese papel correspondía a las instituciones de Bretton Woods y a sus instancias intergubernamentales. Detrás de la controversia yacía la cada vez más obvia caducidad del sistema de

\footnotetext{
${ }^{13}$ Véase, por ejemplo, Naciones Unidas (2009). Esta Comisión, presidida por el profesor Joseph Stiglitz, recomienda, entre muchos otros puntos, la creación de lo que llama un "Consejo de Coordinación Económica Mundial” (Naciones Unidas, 2009, pp. 90-97).

${ }^{14}$ Para los informes emanados de la última reunión del G-20, celebrada en Pittsburgh, EE.UU., el 24 y 25 de septiembre de 2009, véase: https:// www.pittsburghg20.org/PDFs/G20Report1109.pdf
} 
gobernabilidad de las instituciones de Bretton Woods, sobre todo en relación con la ponderación del voto en el seno de sus Directorios Ejecutivos. Asimismo, jugó un papel igualmente importante el cuestionamiento de las políticas del Banco Mundial, el Fondo Monetario Internacional, y lo que hoy es la Organización Mundial del Comercio (OMC). Por cierto, tampoco se escapan de esa crítica las Naciones Unidas, siendo la principal reivindicación la reforma del Consejo de Seguridad.

Las economías desarrolladas, lideradas en este caso por la delegación de los Estados Unidos (en los meses finales de la Administración Bush), se resistían tenazmente a celebrar semejante Conferencia; la parte contraria, en la que Cuba, la República Bolivariana de Venezuela y Nicaragua, entre otros, jugaron un papel proactivo, insistió con igual fervor en el particular. Al final hubo un compromiso, al acordarse en la Conferencia Internacional sobre la Financiación para el Desarrollo, celebrada en Qatar, Doha, en diciembre de 2008, que: "las Naciones Unidas celebrarán una conferencia al más alto nivel sobre la crisis financiera y económica mundial y sus efectos sobre el desarrollo", siendo claves estas últimas palabras, ya que aquellos países que le niegan protagonismo a las Naciones Unidas en temas financieros no cuestionan su papel en materia de promoción del desarrollo (Naciones Unidas, 2008, párrafo 79).

La preparación de la Conferencia recorrió un camino muy accidentado, sobre todo porque esta se colocó bajo la égida del Presidente de la Asamblea General, ejercida en aquel momento por el Padre Miguel D'Escoto de Nicaragua, quien aprovechó su tribuna para influir en el contenido de la Declaración que habría de emanar de la Asamblea General. Las pugnas que surgieron tempranamente en torno del producto final de la Conferencia no solo tuvieron el corte tradicional Norte-Sur, sino que también se dieron en el interior del Grupo de los 77 más China, y también dentro de los países de América Latina y el Caribe. No es del caso en este artículo entrar en un relato detallado sobre el particular, pero sí vale la pena orientar al lector hacia el texto del borrador de propuesta de Declaración política que el Presidente de la Asamblea General sometió a la membrecía el 8 de mayo de 2009, en sustitución de una versión más "blanda" elaborada por los dos facilitadores que él había designado anteriormente para esa tarea (los Embajadores de los Países Bajos y de San Vicente y las Granadinas). ${ }^{15}$

En ese proyecto de Declaración se proyectaba a la Conferencia como un evento comparable a la histórica Conferencia de Bretton Woods de 1944, y se pretendía colocar el nuevo ordenamiento financiero y monetario bajo el foro universal de las Naciones Unidas (el "G-192"), en un contexto conceptual e ideológico que no reflejaba precisamente el punto de vista de las principales potencias económicas del planeta, y ni siquiera de muchos países en desarrollo. Se produjo una rebelión contra el texto, el Presidente tuvo que recular, y finalmente la Conferencia se llevó a cabo, sin mayores sobresaltos, dando origen a una Declaración diplomáticamente aceptable para todas las partes, pero poco relevante para la acción a futuro. ${ }^{16}$

El punto a resaltar es que la creciente diferenciación de enfoques sobre la mejor manera de abordar el desarrollo también se transmitió a la posición que los países de la región adoptaran con respecto a temas económicos en los principales foros internacionales. Aún está por verse si esta nueva diferenciación es saludable para las Naciones Unidas. Por ahora, lo que ha revivido son temas que se debatían hace 35 años en el marco de "un nuevo orden económico internacional", con un fuerte tono de denuncia de los países del "Sur" en contra de los países del "Norte", y demandas de "emparejar la cancha" de la economía internacional para dar similares oportunidades a todos los países de participar en sus beneficios. ${ }^{17}$

\footnotetext{
15 Estos documentos están disponibles en el portal de las Naciones Unidas, en: http://www.un.org/ga/president/63/interactive/uneconference.shtml

${ }^{16}$ Resolución 63/303 de la Asamblea General. Documento final de la Conferencia sobre la crisis financiera y económica mundial y sus efectos en el desarrollo. Acaso la conclusión potencialmente más significativa de la Conferencia fue el establecimiento de un grupo de trabajo especial de composición abierta, para hacer un seguimiento de las cuestiones que figuran en el documento final (véase Resolución 63/305).

${ }^{17}$ Resolución 63/224 del 19 de diciembre, 2008, "Hacia un nuevo orden económico internacional".
} 


\section{VII \\ Síntesis y conclusiones}

En conclusión, las crisis de 2008 no solo repercutieron profundamente en las economías y el financiamiento, sino también en las ideas. El cuestionamiento al paradigma vigente durante alrededor de dos décadas, que había cobrado un creciente número de adeptos, se vio intensamente exacerbado como consecuencia de la crisis. Entre las muchas consecuencias que se podrían vaticinar para los próximos años, se puede mencionar lo siguiente:

Primero, al parecer concluyó un período que permitía un elevado nivel de consenso en torno de un paradigma económico, al menos en su línea gruesa de ejecución, para dar paso a un período de dudas, cuestionamientos y ensayo de alternativas.

En consecuencia, y en segundo lugar, habrá un debate más intenso sobre estrategias y políticas de desarrollo, impulsado por el retroceso que la crisis significó para muchos países. Ese debate será saludable en la medida en que no conduzca a enfrentamientos innecesarios entre países o entre distintos grupos de un mismo país.

Tercero, y como corolario de lo anterior, se abren nuevos espacios de trabajo para la CEPAL cuya Secretaría puede contribuir al debate con iniciativas propias y como vehículo que facilite el intercambio de opiniones $\mathrm{y}$ de vivencias.

Al mismo tiempo, y en cuarto lugar, el surgimiento de la "Alternativa Bolivariana", que invoca la unidad latinoamericana y del Caribe, paradójicamente podría conducir a un escenario de división en lugar de aglutinamiento, al introducir factores divergentes en el interior de agrupaciones de países históricamente unidos en torno de valores e intereses comunes. Llama la atención que la Alianza Bolivariana para los Pueblos de Nuestra América ha crecido lo suficiente como para participar en cada uno de los procesos formales de integración vigentes: en Centroamérica (Nicaragua), en la Comunidad del
Caribe (Antigua y Barbuda, Dominica y San Vicente y las Granadinas) y en el Mercosur (al ratificarse la adhesión de la República Bolivariana de Venezuela). Desde luego, ese escenario no necesariamente se dará en la práctica cotidiana, pero sí constituye una nueva realidad de diferenciación que antes no existía. Ello, a su vez, seguramente dará lugar a disputas y tensiones más acentuadas de las que se percibían, por ejemplo, en los años noventa.

En quinto lugar, con la creciente diferenciación de posiciones se introdujo un nuevo sesgo de confrontación en foros multilaterales cuyo rasgo principal suele ser la cooperación. Ello ha hecho cada vez más difícil llegar a acuerdos universales, como lo puso de relieve la Conferencia al más alto nivel sobre la crisis financiera y económica mundial y sus efectos sobre el desarrollo en julio de 2009, y nuevamente la Conferencia de las Naciones Unidas sobre el Cambio Climático, cuyos resultados relativamente magros — aun así rechazados por los países del ALBA- se anunciaban justo cuando se cerraba este artículo. ${ }^{18}$

Por último, es probable que se esté entrando de nuevo, como ha ocurrido en períodos previos de transición, en una etapa marcada por cierta perplejidad, en contraste con la relativa seguridad que caracterizaba el accionar de los encargados de formulación de políticas en los años previos a 2008. Ello será también uno de los legados de las crisis de 2008.

\footnotetext{
18 Véase el Comunicado especial sobre cambio climático de la VIII Cumbre del ALBA con miras a la XV Conferencia de las Partes en Copenhague, 14 de diciembre, 2009, así como la intervención del Presidente de la República Bolivariana de Venezuela, Hugo Chávez Frías, en la Conferencia de las Naciones Unidas sobre el Cambio Climático, en Copenhague, Dinamarca, el 16 de diciembre de 2009 http://www.alternativabolivariana.org/.
} 
Banco Mundial (2005), Informe sobre el desarrollo mundial, 2006: equidad y desarrollo, Washington, D.C.

CEPAL (Comisión Económica para América Latina y el Caribe) (2009a), Panorama de la inserción internacional de América Latina y el Caribe 2008-2009. Crisis y espacios de cooperación regional (LC/G.2413-P), Santiago de Chile, agosto. Publicación de las Naciones Unidas, $\mathrm{N}^{\circ}$ de venta: S.09.II.G.62.

(2009b), La reacción de los gobiernos de las Américas frente a la crisis internacional: una presentación sintética de las medidas de política anunciadas hasta el 31 de agosto de 2009 (LC/L.3025/Rev.4), Santiago de Chile, septiembre.

(2009c), "El impacto "real" de la crisis económica global: una visión desde América Latina y el Caribe", presentación de la Secretaria Ejecutiva de la CEPAL en el Seminario inaugural de la Escuela de verano sobre economías latinoamericanas (Santiago de Chile, 5 de agosto) [en línea] http://www.cepal. org/cgi-bin/getprod.asp?xml=/noticias/paginas/8/33638/P33638. xml\&xsl=/tpl/p18f-st.xsl\&base=/tpl/top-bottom.xsl

(2009d), El arco del Pacífico latinoamericano después de la crisis: desafíos y propuestas (LC/R.2156), Santiago de Chile, noviembre.

(2009e), Balance preliminar de las economías de América Latina y el Caribe 2009 (LC/G.2424-P), Santiago de Chile, 10 de diciembre. Publicación de las Naciones Unidas, $\mathrm{N}^{\circ}$ de venta: S.09.II.G.149.

(2009f), Panorama social de América Latina, 2009 (LC/G.2423-P), Santiago de Chile.

(2007a), Estudio económico de América Latina y el Caribe 2006-2007 (LC/G.2338-P), Santiago de Chile. Publicación de las Naciones Unidas, $\mathrm{N}^{\circ}$ de venta: S.07.II.G.2.

(2007b), Balance preliminar de las economías de América Latina y el Caribe 2007 (LC/G.2355-P), Santiago de Chile. Publicación de las Naciones Unidas, $\mathrm{N}^{\circ}$ de venta: S.07.II.G.161.

(2006a), Estudio económico de América Latina y el Caribe 2005-2006 (LC/G.2314-P), Santiago de Chile. Publicación de las Naciones Unidas, $\mathrm{N}^{\circ}$ de venta: S.06.II.G.2.

(2006b), Panorama de la inserción internacional de América Latina y el Caribe, 2005-2006 (LC/G.2313-P), Santiago de Chile, septiembre. Publicación de las Naciones Unidas, $\mathrm{N}^{\circ}$ de venta: S.06.II.G.67.

(2000), La economía cubana: reformas estructurales y desempeño en los noventa, México, D.F., Fondo de Cultura Económica.

(1998), El pacto fiscal: fortalezas, debilidades, desafíos (LC/G.2024), Santiago de Chile, abril.

(1997), Panorama social de América Latina, 1996

(LC/G.1946-P), Santiago de Chile, febrero. Publicación de las Naciones Unidas, $\mathrm{N}^{\circ}$ de venta: S.97.II.G.4.

(1996), Fortalecer el desarrollo: interacciones entre macro y microeconomía (LC/G.1898/Rev.1-P), Santiago de Chile, julio. Publicación de las Naciones Unidas, $\mathrm{N}^{\mathrm{o}}$ de venta: S.96.II.G.2.

(1994a), El regionalismo abierto en América Latina y el

Caribe: la integración económica al servicio de la transformación productiva con equidad (LC/G.1801/Rev.1-P), Santiago de Chile, enero. Publicación de las Naciones Unidas, $\mathrm{N}^{\circ}$ de venta: S.94.II.G.3

(1994b), Equidad y transformación productiva: un enfoque integrado (LC/G.1701/Rev.1-P), Santiago de Chile, febrero. Publicación de las Naciones Unidas, $\mathrm{N}^{\mathrm{o}}$ de venta: S.92.II.G.5.

(1990), Transformación productiva con equidad: la tarea prioritaria del desarrollo de América Latina y el Caribe en los años noventa (LC/G.1601-P), Santiago de Chile, marzo. Publicación de las Naciones Unidas, $\mathrm{N}^{\circ}$ de venta: S.90.II.G.6.

Comisión para el Empoderamiento Jurídico de los Pobres (2008), La ley: la clave para el desarrollo sin exclusiones, Nueva York, Programa de las Naciones Unidas para el Desarrollo (PNUD).

Fernández, Fernando (1994), "La CEPAL y el neoliberalismo: entrevista a Fernando Fajnzylber", Revista de la CEPAL, Nº 52 (LC/G.1824-P), Santiago de Chile.

Fishlow, Albert (1985), "The state of Latin American economics", Economic and Social Progress in Latin America: 1985 Report, Washington, D.C., Banco Interamericano de Desarrollo.

La Fuente, Mario y Pedro Sáinz (2001), "Participación de los pobres en los frutos del crecimiento", Revista de la CEPAL, $\mathrm{N}^{\circ} 75$ (LC/G.2150-P), Santiago de Chile, diciembre.

López Calva, Luis y Nora Lustig (2009), "The recent decline in inequality in Latin America: Argentina, Brazil, Mexico and Peru", documento presentado en el Panel de Economía celebrado en la Universidad Torcuato di Tella.

Lustig, Nora (2009), "Poverty, inequality and the new left in Latin America", Woodrow Wilson Update on the Americas, $\mathrm{N}^{\circ} 5$, Washington, D.C., Woodrow Wilson International Center for Scholars, octubre.

Lustig, Nora y Darryl McLeod (2009), Are Latin America's New Left Regimes Reducing Inequality Faster?, Washington, D.C., Woodrow Wilson Center for International Scholars, Latin American Program, julio.

Madariaga E., Aldo (2009), Redefiniendo los espacios de la política social: reducción de la pobreza, transferencias y corresponsabilidades, documento presentado en el Taller de expertos "Protección social, pobreza y enfoque de derechos: vínculos y tensiones" (Santiago de Chile, 5 y 6 de noviembre de 2009).

Naciones Unidas (2009), Informe de la Comisión de Expertos del Presidente de la Asamblea General de las Naciones Unidas sobre las reformas del Sistema Monetario y Financiero Internacional, Nueva York, 21 de septiembre.

(2008), Conferencia internacional de seguimiento sobre la financiación para el desarrollo encargada de examinar la aplicación del Consenso de Monterrey (A/CONF.212/L.1/ Rev. 1), Nueva York, diciembre.

Ocampo, José Antonio (2009), "Rethinking global economic and social governance", Nueva York, Universidad de Columbia, septiembre.

Rossi, Fernando Ramón (2009), “QQué es el ALba?” [en línea] http:// www.alternativabolivariana.org, noviembre.

Soares, Sergei y otros (2009), "Conditional cash transfers in Brazil, Chile and Mexico: impacts upon inequality", Estudios económicos, número extraordinario, México, D.F., El Colegio de México, febrero.

Torres Olivos, Miguel (2006), "Fernando Fajnzylber: una visión renovadora del desarrollo de América Latina", serie Libros de la CEPAL, No 92 (LC/G.2322-P), Santiago de Chile, noviembre. Publicación de las Naciones Unidas, $\mathrm{N}^{\mathrm{o}}$ de venta: S.06.II.G.124. 